TANGIBLE CULTURAL ANALYTICS:

USING AUGMENTED REALITY TO RESEARCH CULTURAL ARTIFACTS

$$
\text { by }
$$

\title{
Zeeanna Ibrahim
}

Honours Bachelor of Global Business and Digital Arts, University of Waterloo, 2016

\author{
A Major Research Project \\ presented to Ryerson University \\ in partial fulfilment of the \\ requirements for the degree of \\ Master of Digital Media \\ in the program of Digital Media
}

Toronto, Ontario, Canada, 2019

(C) Zeeanna Ibrahim, 2019 


\section{AUTHOR'S DECLARATION FOR AN ELECTRONIC SUBMISSION OF AN MRP}

I hereby declare that I am the sole author of this MRP. This is a true copy of the MRP, including any required final revisions.

I authorize Ryerson University to lend this MRP to other institutions or individuals for the purpose of scholarly research.

I further authorize Ryerson University to reproduce this MRP by photocopying or by

other means, in total or in part, at the request of other institutions or individuals for the purpose of scholarly research.

I understand that my MRP may be made electronically available to the public. 
TANGIBLE CULTURAL ANALYTICS:

USING AUGMENTED REALITY TO RESEARCH CULTURAL ARTIFACTS

Zeeanna Ibrahim

Master of Digital Media

Digital Media

Ryerson University, 2019

\begin{abstract}
Research has shown that cultural heritage researchers encounter a number of challenges during their research process when working with artifacts and ephemera. Their current processes can be costly and time consuming, and include extensive amounts of both online and offline research. This MRP aims to aid researchers during their research process by providing a digital solution to ease some of the pain points that they currently face. This digital solution is in the form of an augmented reality mobile application. This paper will analyze the definition of augmented reality and how it is currently used in the cultural sector, identify the problems researchers face through primary and secondary research, provide a solution to those challenges, describe the user flow of the mobile application, and use the Design Thinking model to explain the design decisions made for this prototype. This MRP is in collaboration with the Ryerson Synaesthetic Media Lab and the University of Toronto's Thomas Fischer Rare Book Library, and was completed with group members Daniella Kalinda and Ben Ashley.
\end{abstract}




\section{ACKNOWLEDGEMENTS}

Ali Mazalek for being my primary supervisor and for helping me stay on the right track throughout the course of this MRP. Thank you for accepting me into the Ryerson Synaesthetic Media Lab and for allowing me to pursue this topic with the TCA team.

Namir Ahmed, Rob Blain, and Tihmily Li for being my amazing second readers and for rising above the expectation. The role of a second reader is provide minor edits and revisions to the MRP paper, however my second readers were there to support me throughout this process to make sure I would succeed. Am Sagarwala for being a guide throughout this entire year in the MDM program. The members of the TCA team who put their time and effort into pursuing this project. Salman for his love of history and museums. Thank you for encouraging and supporting me during this process, and for accompanying me on my research visits to various museums. Satvika for her tremendous skills in design and user research. Thank you for showing me the way to achieve beautiful, simplistic, and functional design. My mom for supporting me during my Masters journey this year. 


\section{Group CONTRIBUTION}

\section{Zeeanna}

During the interview process with researchers and cultural heritage scholars, main challenges and pain points of the research process were discovered, which included artifacts not being accessible online, artifacts being mis-catalogued online, and not having the ability to travel several times a year. The digital solution that has been proposed for this MRP is a tangible augmented reality mobile application that allows researchers to access artifacts remotely. During the interviews, researchers described the main activities that took place during the research process, and these included searching online for artifacts and archives, organizing data into databases or filing systems, and collaborating with colleagues. This mobile app prototype aims to reflect these common actions and occurrences as features in the app. The effectiveness of user experience design depends on many factors including having accurate information, the approach to design, and the methods followed (Adikari, 2013). The principles of Design Thinking were followed when designing and prototyping this app.

\section{Daniella}

The field of cultural heritage has seen an increase in the use of innovative technologies, particularly augmented reality and virtual reality, to increase public interest in cultural heritage. Due to this, museums and cultural heritage sites have shown greater feedback in visitor experience ( $\mathrm{He}, \mathrm{Wu}$, and $\mathrm{Li}, 2018)$. At the academic level, however,

cultural scholars have not experienced the same level of innovation and still rely heavily on old methods of research. In order to design a relevant and intuitive digital solution, we conducted interviews with cultural scholars to know their current practices and discover their pain points. From these interviews we found that researchers have trouble accessing cultural heritage items because they are not all available online and are not well catalogued. This process is laborious for researchers. So, we decided to facilitate access to cultural heritage from remote places by providing a tangible experience to the digital 
search. This involves a multi-target cube where scholars have a $3 \mathrm{D}$ visualization of the item as well as descriptions, recommendations, and sharing options.

\section{Ben}

Recommender systems were invented in 1992, in the early days of the Internet (Boehmer, Jung, 2015). Using metadata attributes to group together similar items, they have become a staple for e-commerce sites and applications alike. Yet in the world of academia and research, it seems that their full potential has yet to be realized. Ben's project discussed how recommender systems can benefit an augmented reality application designed for cultural research. By conducting a literature review and observing the pros and cons to a number of different types of systems, he decided to implement a contentbased recommender system without a user profile. For this prototype, he developed an equation based on using 14 sample artifacts taken from the Oriental Institute at the University of Chicago. The equation works by comparing one object against another and finding out the relevance percentage. The percentages would then be ranked, and the top four would be the four artifacts recommended in the application.

The way each value was determined was by looking at the relative similarity between each attribute. For the Time Period values, we associated 0 with the earliest time period, the Bronze Age. We associated 8 with the latest time period, WWII. For the Country of Origin values, we decided to associate each value with relative distance between each country. For the material timeline, we associated 0 with copper, 1 with bronze, 2 with silver, and 3 with gold. Each attribute was given the same weight. This may change in future iterations as the user may be given a choice on which attribute he or she may want to put more emphasis on. Ben further discusses in his paper on how we can further utilize recommender systems in a complex manner. This would mean implementing user profiles, a rating system, machine learning, and possibly artificial intelligence. There are numerous possibilities. 


\section{DEFINING TERMS}

The terms artifact, ephemera, and archives, will be used several times throughout this paper. Although artifacts and ephemera stand for the same idea, they do carry their own definitions. According to the Merriam-Webster dictionary, an artifact is an object showing human workmanship or modification (Merriam-Webster Dictionary, 2019). They refer to the solid, tangible, 3D objects that have been preserved and passed down through time and have become a part of cultural heritage. Ephemera refers to a collection of printed materials created for a specific purpose and for temporary use, including photographs, postcards, and brochures (Merriam-Webster Dictionary, 2019). The preservation of both artifacts and ephemera allow for first-hand access to its original context and state. Artifacts and ephemera are stored in archives, which can be defined as an institution that holds and preserve collections and historical materials (MerriamWebster Dictionary, 2019). For the purpose of this paper, the terms artifact, ephemera, and cultural heritage items will be used interchangeably.

The terms researcher, curator, and cultural heritage scholar will be used several times throughout this paper. Researcher refers to someone who carries out academic or scientific research. Curators are responsible for assembling, cataloguing, and presenting archives and collections, usually in a museum or gallery. Cultural heritage refers to the legacy of tangible artifacts and intangible attributes of a society that have been inherited from generations and preserved in the present, therefore in this case, a cultural heritage scholar is equivalent to a historian or a curator (UNESCO, 2017). For the purpose of this paper, the terms researcher, curator, and cultural heritage scholar will be used interchangeably. 
Author's Declaration $\quad$ ii

Abstract iii

Acknowledgements $\quad$ iv

Group Contribution $\quad$ V

Defining Terms vii

Table of Contents viii

List of Tables $\quad$ ix

List of Figures $\quad \mathrm{x}$

List of Appendices $\quad$ xi

Introduction $\quad 1$

What is Augmented Reality 1

Why Augmented Reality in Museums 2

Examples of Augmented Reality in Museums 3

Problem $\quad 5$

Solution $\quad 9$

Multi-Target Cube 9

UX \& UI 12

User Flow 12

Design Thinking Model 14

$\begin{array}{ll}\text { Future Work and Conclusion } & 18\end{array}$

$\begin{array}{ll}\text { Appendix } & 20\end{array}$

$\begin{array}{lr}\text { Works Cited } & 30\end{array}$ 
Table 1: Advantages and Disadvantages of Researching Online

Table 2: Advantages and Disadvantages of Visiting Archives 
Figure 1: Multi-Target Cube 10

Figure 2: Ephemera displayed with AR 11

Figure 3: User Flow of the App Prototype 13

Figure 4: Original Prototype Design 15

Figure 5: Design Thinking Model 16 
$\begin{array}{lr}\text { Interview } 1 & 20\end{array}$

Interview $2 \quad 21$

Interview $3 \quad 24$

$\begin{array}{ll}\text { Interview } 4 & 26\end{array}$

Interview 5 


\section{INTRODUCTION}

Culture and technology are two areas where the particular blend of creativity and technological skill is the driving force behind pushing boundaries, making new experiences, and creating opportunities. The cultural sector is taking strides towards embracing new technologies, which is highly beneficial in a technology driven society. Augmented reality in particular, has captivated audiences with its ability to adapt, connect, and apply to new audiences. Museums have started to recently experiment with $\mathrm{AR}$, trying to create bridges between the artifacts and their visitors. Currently, the use of $\mathrm{AR}$ in museums is for the purpose of engagement, interactivity, and enhancing the visitor experience (Ding, 2017). While these digital technologies are present in the cultural sector, it is so far only being used for the outward facing public, and not for research or academia. Through primary research, some of the challenges that researchers faced while studying artifacts and ephemera were discovered. The goal of this MRP was to find a way to use emerging technologies to create a digital solution to facilitate the research of artifacts and ephemera, in order to ease researchers of some of their pain points. A digital solution in the form of an AR mobile app was designed to allow researchers to have a more fulfilling research experience. This paper explains the technology used to create the solution, how it is beneficial for researchers, the user flow of the mobile app, and the reasoning and design decisions behind the features of the user interface.

\section{What is Augmented Reality}

The best way to describe augmented reality is the blending of two realms; the real physical world and the digital world you see on a device combined on an interface that layers them together. This layering of information on top of objects, places, or products, leaves you with a seamless experience that provides countless possibilities. In his article titled "Museums are the Best Place to Find Innovation in AR", Brendan Ciecko describes augmented reality as "the digital magnifying glass that enables us to explore the details behind every word, letter, and punctuation mark," as if it were being compared to a book 
(Ceicko, 2018). Most instances of AR are experienced through a see-through device that can be worn on the head or through a handheld device. AR systems use some of the same technologies as Virtual Reality, but the key difference is that while VR aims to replace a real world environment, AR is used to enhance or supplement it (Feiner, 2002). Museums in particular are starting to become some of the most exciting places to test augmented reality. Over time, museums have adapted to different ways in conveying information to visitors by using audio guides, interactive screens, and wall labels. The intent has been to provide in-depth information to support different learning styles. A further way to engage visitors has been to diversify these experiences based on different audiences (Petrelli, 2013). Augmented reality is the newest form of interaction that has been introduced into the world of history and culture (Ceicko, 2018).

\section{Why Augmented Reality in Museums}

Museums are known for taking historic events and displaying them in a contemporary setting for the purpose of information sharing and enjoyment for the public. Museums are constantly making an effort to explore different ways to connect with their audience, and one way to do this is to incorporate augmented reality experiences (Kohles, 2018). In her paper titled "Augmented Reality in Museums," Mandy Ding states that the appeal for AR in museums is clear - the technology allows media content to be layered upon real environments, which provides a way for museums to "bring collections to life." Through mobile apps, museums can provide additional information about exhibits or the museum itself, or even create a personalized guide for the visitor. According to the 2015 Trendwatch Report, personalized learning has become one of the most prominent global trends in recent years (Ding, 2017). Allowing a visitor to choose how they view something is an important part of personalization and it is a suitable way to meet the needs of the visitor, for example, by making an exhibit more accessible through the use of AR. Several benefits have been seen through the use of augmented reality apps in museums, including presenting the user with additional information, acting as a tool for higher engagement, and a creative a tool for learning. Museums enable visitors to explore information about the artwork themselves by using 
the suggested paths or guides. The option of having an AR display allows the visitor to not only gain knowledge of the displayed artwork, but to also interact with and absorb layers of information on top of the work. According to the 2014 Digital Revolution report, $69 \%$ of people brought a mobile device with them to their last museum visit (Ding, 2017). Visitors are already accustomed to holding up their mobile phones to take pictures, therefore scanning an AR project with the device easily fits into the existing museum experience.

\section{Examples of Augmented Reality in Museums}

The Jackson Pollock exhibit at the Museum of Modern Art in New York has been turned into an augmented reality playground; to those who know how to transform it. To the average viewer, the painting gallery remains unchanged, however when viewed through the museum's app, Pollock's paintings are either remixed or entirely replaced. The app in question is called MoMAR, and it uses augmented reality to overlay art onto existing work and frames. Damjan Pita, the brains behind MoMAR, explained that certain cultural values are held by an "elite" part of society, which is why very few may know how to access it (Katz, 2018). However, this "secret" which may only be seen by the "elite" is soon to become a global movement. Artists from Los Angeles and Germany are hoping to use MoMAR's software to enact a virtual takeover in museums in their own cities. Tools like Apple's AR kit and Google's ARCore have made it easy for developers to build and distribute AR apps (Katz, 2018). The Cleveland Museum of Art has created one of the most well known AR apps for an art museum. ArtLens 2.0, which launched in 2016, acts as a dynamic catalogue of every piece of art on display at the museum, providing its name, date, information, and location. The app also contains a mapping and beacon technology, enabling visitors to discover new pathways through the museum's exhibits. The research team at the Cleveland Museum of Art has observed the app's functionality in real time and has conducted interviews to obtain feedback. Their findings have shown that the integration of various technologies has made the museum visit more engaging (Ding, 2017). The Smithsonian's National Museum of Natural History developed an app called Skin \& Bones, which aimed to share untold stories behind the 
museum's most iconic collections. The app allowed the user to simply hold up their phone's camera, and by scanning specific specimens, visitors were able to see their skeletons come to life. The purpose of the app was to make the exhibit more accessible to visitors, make it more enjoyable, and to create an educational experience (Ding, 2017). 


\section{Problem}

Research has shown that stakeholders ranging from museum management, curators, and technology providers, have very different goals when introducing interactive media to museums. Many times, companies creating software and mobile apps try to sell the same solution for different purposes or institutions, which often leads to an unconvincing or generic experience (Petrelli, D). In addition, these softwares are mainly produced with the idea of the typical museum visitor in mind. By shifting the focus from the visitors to the researchers, our goal is to facilitate a new way of researching and communicating cultural heritage digitally to academics, scholars, and curators.

In order to understand the current research methods of cultural heritage scholars, structured interviews were performed with eight individuals who identified as either researchers, curators, or professors from institutions including Ryerson University, the University of Toronto, the Royal Ontario Museum, Mackenzie House, the Museum of Toronto Service, and the Ryerson Image Arts Centre. They were asked to define their practice in their own terms, describe their current methodologies, and the technologies and programs they use during their studies. Through these interviews, two distinct parts of the research process that were prevalent for all researchers were discovered; researching online, and visiting archives. Both important parts of the research process, both with their own challenges and pain points.

According to the interviews, the majority of research is conducted online. It is easily accessible and allows researchers to work remotely, it has a vast amount of information, and it acts as a starting point for many research projects, providing background information for many subjects (Appendix, Interview 2). Many researchers use online searches as a way to determine if a collection is relevant to their study before they make a decision on whether or not they want to travel to see it. Online methods are useful for pre and post travel, as it gives researchers the ability to save and reference their search for a later date (Appendix, Interview 3). Online methods are also useful for 
collaboration. It is simple for researchers to share their work with colleagues across the world to procure feedback or additional information on a specific artifact. Even with all the advantages that are brought with researching online, there are still several disadvantages which act as a challenge. A detriment that was mentioned by almost every researcher interviewed is that online information is often incorrect and mis-catalogued. Institutions and websites only tell you a summary of the information that is available on a specific collection, leaving the researcher with several missing pieces. Some researchers turn to traditional methods and use physical literature to learn about artifacts (Appendix, Interview 4). Online images of artifacts are also low-resolution, colours may be distorted due to lighting conditions, and only one side of an artifact can be seen with a flat online image. The second stage of the research process is visiting archives. $100 \%$ of the researchers interviewed agreed that this was integral to the research process and that it was much "more rewarding to look at the tangible sources" because they are able to collect primary research and make their own observations and archives on the collection, instead of relying on someone else's work (Appendix, Interview 1). As stated earlier, both parts of the research process, being online and visiting archives, have their own benefits and challenges. The tables below describe in detail the advantages and disadvantages of each of these processes.

\section{Advantages and disadvantages of researching online}

\begin{tabular}{|l|l|}
\hline \multicolumn{1}{|c|}{ Advantages } & \multicolumn{1}{c|}{ Disadvantages } \\
\hline $\begin{array}{l}\text { Researching online is easily accessible } \\
\text { to researchers anywhere in the world; } \\
\text { they can work remotely }\end{array}$ & Not enough artifacts available/accessible online \\
\hline $\begin{array}{l}\text { Allows researchers to create their own } \\
\text { catalogues and databases }\end{array}$ & $\begin{array}{l}\text { A large percentage of information available online is } \\
\text { incorrect or mis-catalogued }\end{array}$ \\
\hline $\begin{array}{l}\text { Researchers use online searches as a } \\
\text { way to determine if something is } \\
\text { relevant to their study }\end{array}$ & You are told the stories that institutions and websites \\
\end{tabular}




\begin{tabular}{|l|l|}
\hline Used to find directions and instructions & $\begin{array}{l}\text { Hard to narrow down a search or find a very specific } \\
\text { artifact with the current systems }\end{array}$ \\
\hline Used for collaborating with colleagues & Screen time is taxing and strains the eyes \\
\hline $\begin{array}{l}\text { Opportunity for researchers around the } \\
\text { world to give feedback or additional } \\
\text { information }\end{array}$ & $\begin{array}{l}\text { Many institutions and museums don't have access to } \\
\text { the same resources, which leads to the issue of } \\
\text { artifacts being categorized differently }\end{array}$ \\
\hline $\begin{array}{l}\text { Good for pre-research and post-travel } \\
\text { Researching online can occur overtime, } \\
\text { whereas visiting an archive or seeing a } \\
\text { collection only happens once }\end{array}$ & \begin{tabular}{l} 
Many archives are not fully digitized \\
\hline
\end{tabular}
\end{tabular}

Table 1. The advantages and disadvantages of researching artifacts and ephemera online, as reported by researchers during the interviews conducted for this MRP

Advantages and disadvantages of visiting archives

\begin{tabular}{|l|l|}
\hline \multicolumn{1}{|c|}{ Advantages } & \multicolumn{1}{c|}{ Disadvantages } \\
\hline $\begin{array}{l}\text { Researchers learn more about an object by seeing it } \\
\text { physically }\end{array}$ & $\begin{array}{l}\text { Travelling to visit an archive is time } \\
\text { consuming }\end{array}$ \\
\hline $\begin{array}{l}\text { Researchers are able to learn more about the } \\
\text { construction details of the artifact }\end{array}$ & $\begin{array}{l}\text { Travelling to visit an archive is } \\
\text { costly }\end{array}$ \\
\hline A tangible object is more meaningful than a photo & \\
\hline
\end{tabular}

Table 2. The advantages and disadvantages of visiting archives, as reported by researchers during the interviews conducted for this MRP 
The researchers described the different stages of their research process and informed us of some of the activities that took place during this time. These included the pre-research stage, which primarily starts with an online search, the travelling stage where they embark on a journey to study the archives firsthand, and the post-travel stage where they return to dissect and analyze their findings. During the pre-research and posttravel stages, their activities included searching through online collections and museum databases in order to find a basis for their research, organizing the collected data into their own personal database or filing systems, writing papers or reports on their findings, collaborating with their colleagues and fellow researchers, and making connections between the artifacts based on the properties that were discovered. 


\section{SOLUTION}

After the completion of the interviews, the main challenges faced by researchers were discovered, which included not enough artifacts being accessible online, artifacts being mis-catalogued online, and not having the ability to travel several times a year. The digital solution we have proposed is a tangible augmented reality mobile application that allows researchers to access artifacts remotely.

\section{Multi-Target Cube}

When considering using AR in an app or with an institution, one must consider its intention and purpose. For this prototype, a Multi-Target cube was used to give researchers a tangible experience during their research process, since tangibility and physicality were one of the main points that were iterated by researchers. The AR app is activated by a physical cube with six QR codes, representing different sides of a digitized 3D object. By holding and rotating the cube, the app recognizes and displays an artifact on screen, and the researcher is able to imitate the process of holding said artifact. This method is to be used to enhance the pre-research and post-travel experience by allowing researchers to access the artifacts they are studying without having the physical object in front of them. A cube was chosen to be the tangible aspect due to the fact that the flat sides would work as a multi-target image in Unity. In Vuforia, a "Multi-Target consists of multiple Image Targets in a defined geometric arrangement. The position and orientation of each Image Target within a Multi-Target is defined relative to the origin of the Multi-Target, which is at its volumetric center" (Vuforia Developer Library, 2018). For this app prototype, each side of the cube is an Image Target, and the cube itself is the Multi-Target. "All of the faces of a Multi-Target can be tracked at the same time because they possess a pre-defined pose relative to the Multi-Target origin" (Vuforia Developer Library, 2018). Therefore, when the user turns the cube in this prototype, the AR camera is able to recognize each side of the cube, seamlessly displaying each side of the artifact, as seen in Fig. 1. 

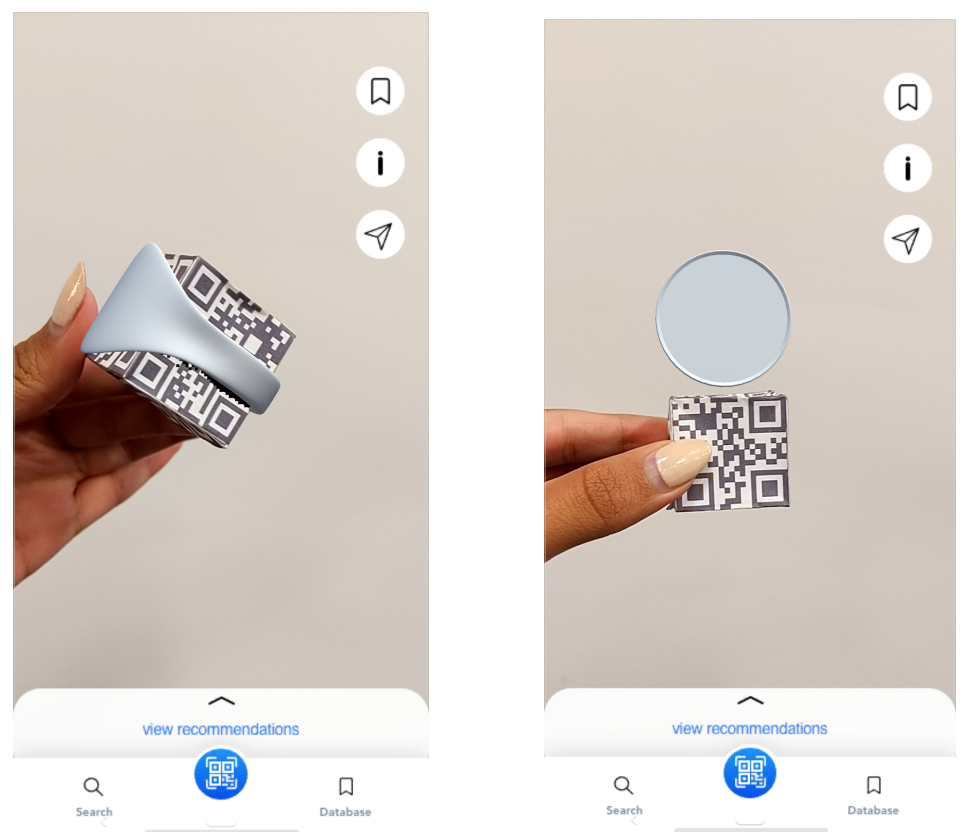

Fig. 1 These images show what the mobile application will display on screen when the app recognizes the $3 D$ Multi-Target cube.

While this application provides many advantages over the current process, primary and secondary research has shown that curators and cultural heritage scholars are conflicted with an idea such as this. They see the potential of digital technologies and augmented reality, and the value that it can add to their research process, however they also see it affecting the values that they care for such as authenticity and tangibility (Petrelli, 2013). In Petrelli's journal article titled "Integrating Material and Digital," she stated that a digital copy of a drawing may support an analysis to a greater level of detail than its paper original, but the feeling of being in the archive and the emotion of touching the paper is a unique experience (Petrelli, 2013). For this reason, this app is not looking to replace the need for travel and the experience of seeing and touching a real tangible artifact, but to be used as an addition to their pre-research and post-travel process. The goal is to recreate and contextualize artifacts, without diminishing the value or authenticity of the original. By augmenting artifacts, we are taking advantage of the power of the physical object and enriching it with the new opportunities that arise through emerging technologies (Petrelli, 2013). It is important to note that this doesn't 
mean researchers will rely on AR alone to make their discoveries, as it still points them to real-world artifacts (Pardes, 2018).
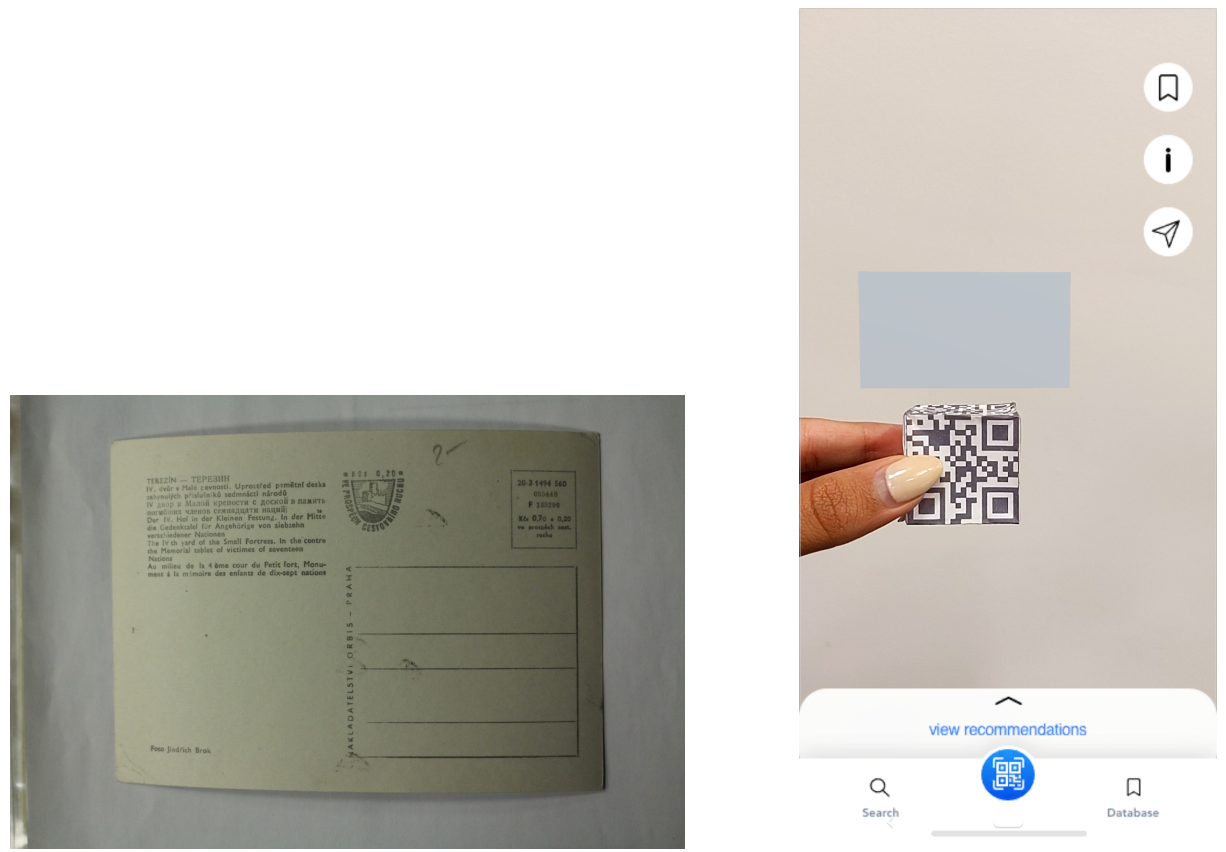

Fig. 2 A photo of a postcard beside an augmented reality digitized version of a postcard to show how an example of ephemera would be viewed on the app. Not to scale.

Another concern that came up with appropriating digital technologies into their existing process is the learning curve. $63 \%$ of the researchers interviewed had previously used AR to show an exhibit or teach a class, but never for their own research. They reported that they didn't know a lot about the technology, as they had started their careers before online methods even existed (Appendix, Interview 1). The switch to online platforms was a major technological change that researchers adapted to, and it is now relied on heavily. Therefore there is still potential for this digital solution, using augmented reality, to be beneficial for this purpose, and especially beneficial for new researchers entering the field as they already have familiarity with the technology. 


\section{UX \& UI}

\section{User Flow}

When the user first opens up the app, they are presented with a splash screen, which gives them instructions on how to use the app (Screen 1). The following screen immediately opens up to the AR camera, where the user can start scanning the cube to find artifacts by holding up the 3D cube to the device's camera (Screen 2). Once the AR camera recognizes the Multi-Target cube, it will display an AR artifact, which the user can interact with by physically moving and rotating the cube (Screen 3). The user will immediately be presented with several options in the form of buttons, allowing the user to save the artifact to their own personal in-app database (Screen 11), read information about the artifact, or send the artifact to a colleague or fellow researcher through native methods including E-Mail, Google Drive, or Dropbox (Screens 4, 5, 6). Users also have the option to search for artifacts within the app through a search interface where they can enter in specific details such as the geographic location, time period, or material (Screens $7,8)$. The app will then display the results of their search on a new screen, where users can tap on an artifact to read more information about it (Screen 9). In addition to the search function, this app also includes a recommendations page (Screen 10). Using the ecommerce model of recommender systems where similar or related items are shown to online shoppers, this system has been adopted into the app by creating a tool which shows researchers new artifacts that have similar properties to the one they are currently viewing. This allows researchers to discover new artifacts they may not have thought of before, therefore expanding their collection and database of objects. The screens below show the user flow of the mobile app, starting at the splash screen and ending at the database screen.

Fig. 3 The following screens show the user flow of the mobile app, starting from the splash screen and ending at the database screen. The functions of each screen are described in the paragraph above. 

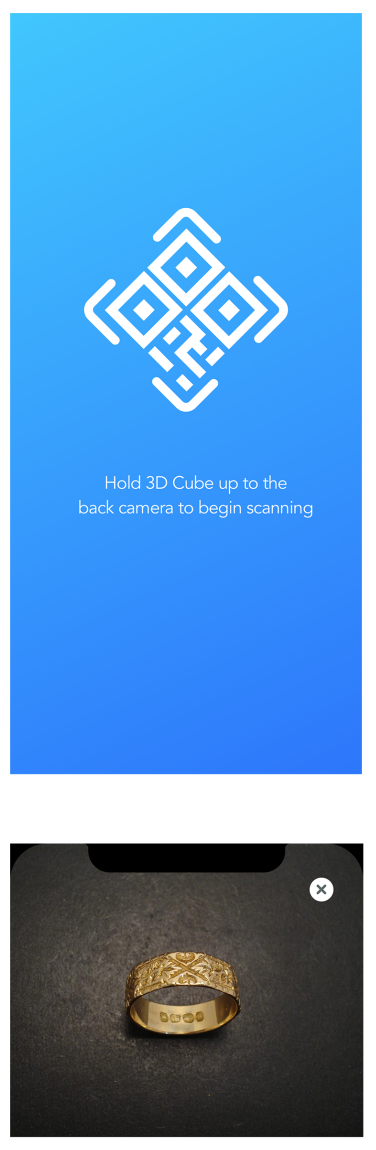

18ct. Gold ring, handcrafted and deeply incised with two recurring motifs,

1892. The One Ring was one of the most

powerful artifacts ever created in Middie-

earth. It was crafted by the Dark Lord

Sauron in the fire of Orodruin, also $k$ hown

as Mount Doom, during the Second Age.

The One Ring was also known as the

Ruling Ring, the Master Ring, the Ring of

forged around the year SA 1600 , within

peoples of Middle-earth under his

dominion.
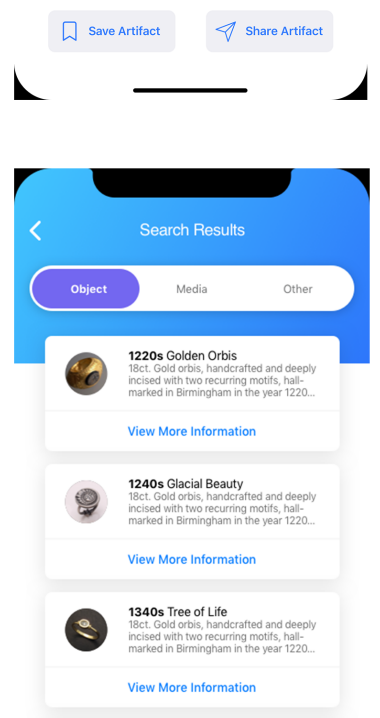

(3)

$\therefore \quad ㅁ$
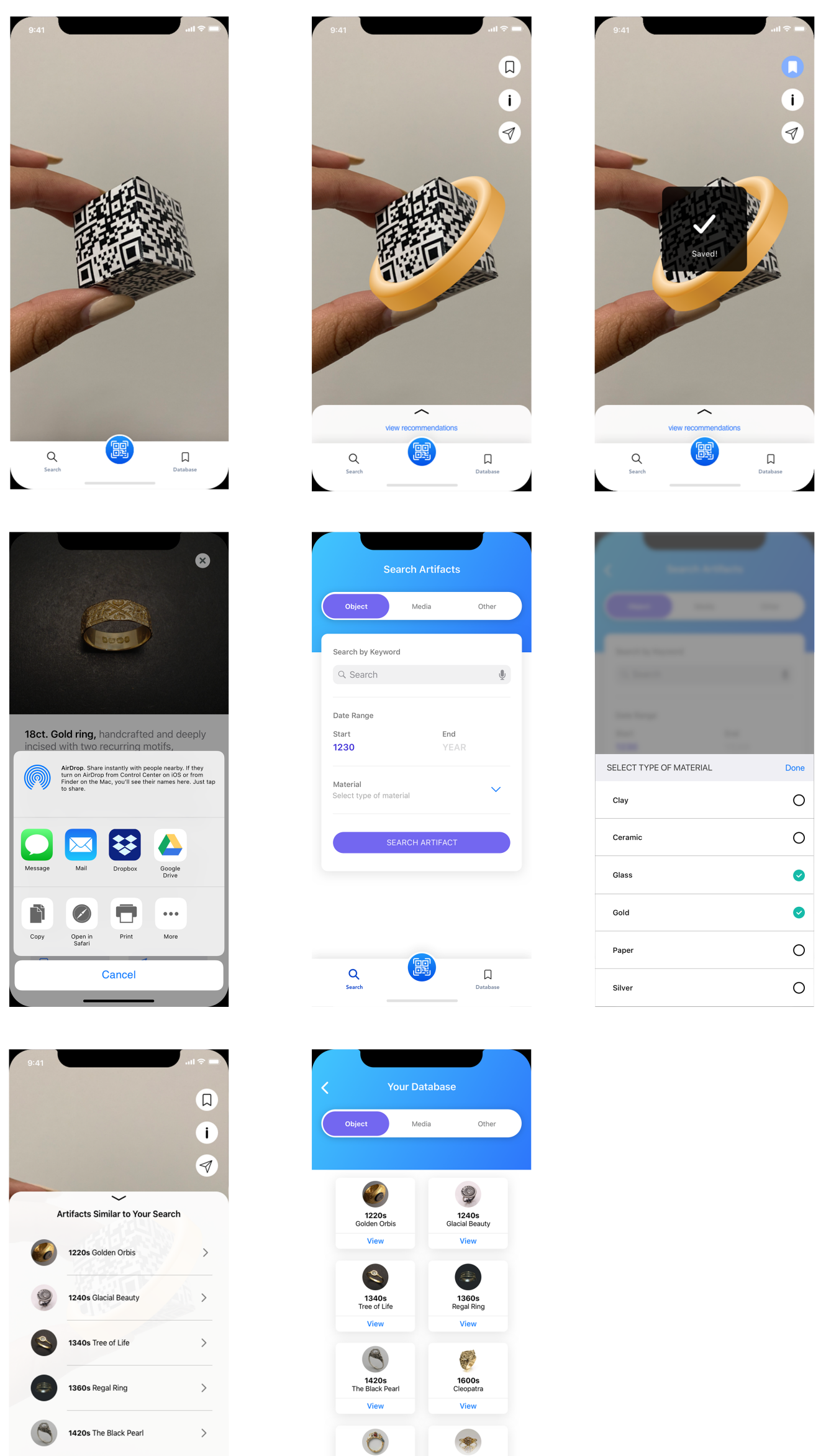

1 逼跑

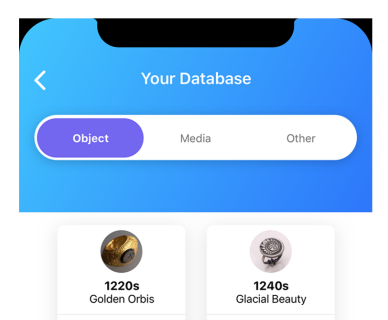

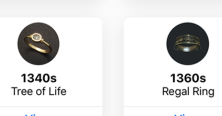

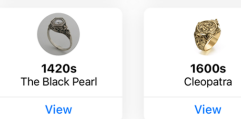

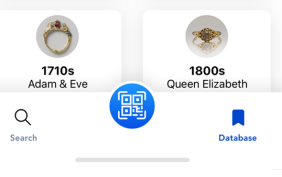




\section{Design Thinking Model}

As mentioned earlier in this paper, the researchers described the main activities they followed during their research process, and these included searching online for artifacts and archives, organizing data into databases or filing systems, writing reports on their findings, collaborating with colleagues, and making connections between artifacts. This mobile app prototype aims to reflect these common actions and occurrences as features in the app. The effectiveness of user experience design depends on many factors including having accurate information, the approach to design, and the methods followed (Adikari, 2013). In order to design this app prototype, the principles of Design Thinking were followed; empathize, define, ideate, prototype, and user test.

Empathize is the first stage of the design process. It allows you to gain an understanding of the problem that is being solved through user research, and it allows you to put your assumptions aside to gain real insight about your users. This is the stage where the 8 interviews with the researchers and curators were conducted in order to gain insight about the research process and to learn about the challenges and pain points.

The define stage is where the results were analyzed and data was organized to find common themes and problems that the researchers experienced. It was found that one of the main issues that researchers faced was accessibility; not having enough information available online, and not having accurate information online. Due to this flaw in accessibility, this prompts many researchers to travel to see the archives in order to report their findings from firsthand and personal data. However this brought up another challenge as not all researchers are available to travel at a given time, as this method is very time consuming and costly.

User experience design is iterative and consumer focused (Silva, 2013). The ideate stage is where the initial wireframes and designs were created with the needs of researchers in mind. This initial prototype was designed on Adobe XD, and it was based on providing a productive user flow for the researcher. In the first two steps, we 
discovered the main activities involved in the research process, which included finding information online to start the research process, organizing their own databases, and collaborating with colleagues. These activities helped to inform the design decisions and functionality of the app. As seen in Fig. 4, these primary features are organized into a hamburger menu for easy accessibility. This design was later developed further in the prototyping stage.

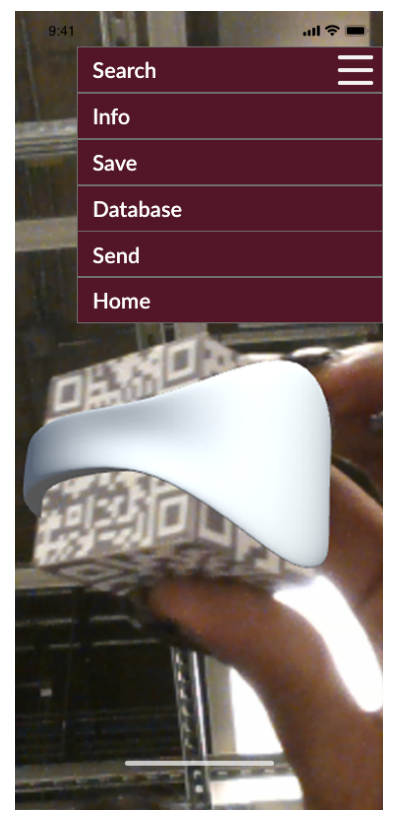

Fig 4. Original prototype design displaying the main features of the mobile app

When creating the second prototype design, several UI kits were examined in order to get a sense of common themes and designs that are both innovative and intuitive. Traditional app layouts and standard UI patterns were used as much as possible so researchers could easily understand the purpose of each element and screen. This prototype was designed for an iOS device, and it was created on Sketch and Invision. Each button on the app uses visual cues and signifiers that illustrate and describe its meaning (See Fig 5, image on the left). Another element that was added to this prototype was visual feedback upon interaction (See Fig. 5, image in the centre). Typically when users interact with an app or a device, they expect that the user interface will respond with the appropriate feedback, whether it's a visual or audio cue, or a change of screen. This feedback is used to tell the user that their interaction was acknowledged and 
registered, and that they have prompted a new action (Babich, 2019). In this prototype, when researchers tap the buttons on the screen, the buttons will be highlighted in blue to indicate that they have been activated. The activated buttons will either take the users to a new screen, open up a new panel, or display a visual signifier on screen (See Fig 5, image on the right).

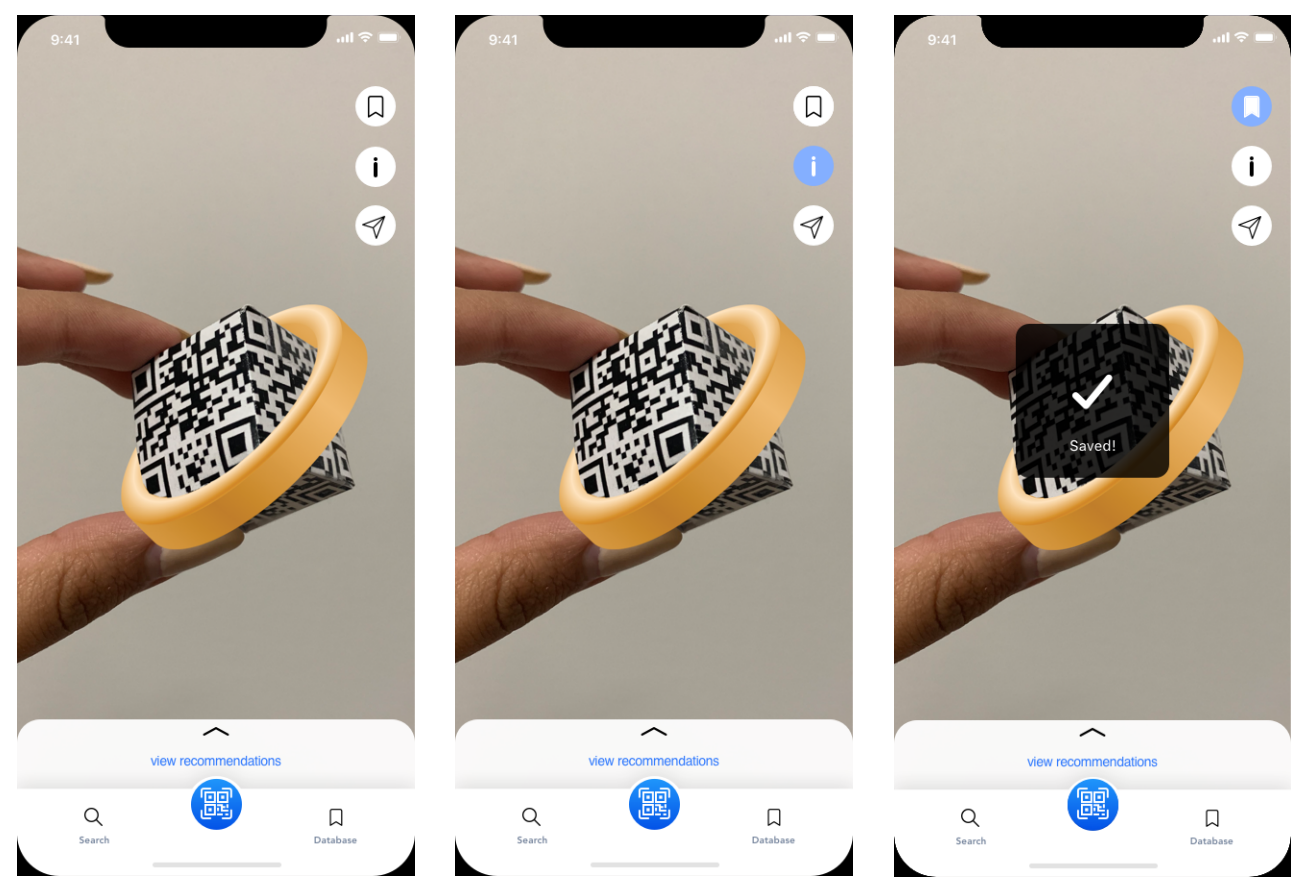

Fig 5. Image on the left. As seen in the first screen of the app, three buttons appear to the right once the AR artifact has been recognized. These symbols act as signifiers for different actions that researchers can interact with. These icons were designed using familiar patterns and symbols.

Image in the centre. When the user taps a button, it will be highlighted in blue to indicate that is has been activated.

Image on the right. In this screen, the user has activated the "Save" button as it is highlighted in blue. As a response to the button being activated, the app displayed a notification to tell the user that the action was registered, and the outcome was completed. 
The user testing stage is the final phase in the Design Thinking model, and it involves testing the design and functionality of the app with real users. In this case, the users are the researchers. For this MRP, the formal user testing stage will be part of the future work, however during informal user testing with colleagues, some challenges were discovered that will help to influence the next prototype. One challenge that was discovered while using the app was trying to hold the tangible cube and navigate the app at the same time. While all the buttons are positioned near the edges and bottom of the screen for easy reach, it is difficult to access with one hand while the other is trying to steadily hold the cube in front of the camera. One way to combat this challenge is to place the phone on a stand, this way one hand can focus on holding the cube and the other can navigate through the app. 


\section{FUTURE WORK AND CONCLUSION}

The result of this MRP provides a digital solution that aims to aid researchers in the research process. This digital solution is a tangible augmented reality mobile application that is to be used to help researchers access artifacts remotely. This solution was created as a result of thorough data collection and careful research as a way to bring emerging technologies into the field of cultural heritage, different from that of museum exhibitions and tools for visitor engagement.

The next step for this MRP is to user test the app prototype with researchers to see if this is a viable solution that would help them overcome the current challenges involved in the research process. The user test would consist of a researcher sitting at a desk and using the Multi-Target cube to experience the AR. A group member would be present during the time of the test to ask questions about the process and receive any feedback.

As stated in the Introduction of this paper, this project is in collaboration with the Ryerson Synaesthetic Media Lab and the University of Toronto's Thomas Fischer Rare Book Library. The Thomas Fischer Library had provided cultural heritage items to the Synaesthetic Media Lab to find a solution in digitizing their artifacts. For this MRP and due to time constraints, the artifacts and images used in this prototype were not of the Thomas Fischer Library. Beyond the MRP, the goal is to find an accurate method to digitize these artifacts. One method in digitizing objects and artifacts that we explored during the course of this MRP was by using the Vuforia Object Scanner. The Vuforia Object Scanner is an Android application that allows users to scan a physical 3D object (Vuforia Developer Library, 2018). The Scanner produces a file with the source data that is recognized when using Vuforia and Unity, and provides a visualization of the object's features across an Object Target. When scanning, the object must be placed on a flat surface, with one end of the object resting on a paper with a specific code from Vuforia. As a result, only the top and sides of the object get scanned, leaving the bottom to be 
empty. Due to this, we could not use the Vuforia Object Scanner for our MRP, but with further research into 3D modelling software, there is potential for this tool to be useful. 


\section{APPENDIX}

In this Appendix you will find excerpts of the interviews conducted for the purpose of this MRP. They are referenced in the paper when describing discoveries made through primary research.

\section{Interview 1}

\section{Interviewer: Daniella Kalinda}

Interviewee: Supervisor of Collections and Outreach with the City of Toronto, Supervisor at Market Gallery and St. Lawrence Market

D: Can you give us a bit of a ratio of how much you handle physical archives vs. researching about them online?

N: I guess, I may be a bit old school, I'm 42, so when I was trained, when I was in University, when I was doing my undergrad and Master's degree there wasn't a lot online so we were still looking at paper resources. So we were still looking at primary source archival documents or indexes or even reproductions of city directories and stuff, but you were still always looking at a physical object. But over the course of my career and over the last couple of years, the accessibility of online documents has increased. I find that I use them both because I find that you get different results from both ways of research. Yeah, I find that initially, even initially my search is probably online sources because it is easiest. You're at your desk and you want to get a basic background, you want to see what's out there. But then I start to look at archival sources that are not accessible online and then I go and consult them, and then sometimes I go back to the online one because sometimes things will become apparent to me in the tangible documents that weren't initially and I'll find things that I didn't reach through other things through that. 
D: What would you say are the top 3 problems that you have either with researching online or when researching with ephemera, either or?

N: I would say that researching online, I would say that maybe because it's also cursory in a way that I tend to be very directed. So I'm asking a question that I want an answer to. I'm getting results or I'm not getting results. Finding...you know the find function is ...really valuable. But I find what happens with a tangible source is that you tend to meander. You tend to be a little less direct because you tend to search in that way you can't search a paper document.

$\mathrm{N}$ : So I find that the online source, you're asking the questions you already know are the questions. Whereas when you look at a tangible source, you may be encountering questions you didn't know were questions, so I find that again the two together are useful. But I find that I do feel somewhat limited. I find it more rewarding to look at tangible sources I think. I find that I get more of a background, that I may be looking at things that I wasn't prepared for or wasn't expecting or wasn't looking for. Whereas I find online that I find what I was looking for. It tends to be narrower. Maybe also as I get older, my eyes, my vision. Looking at a screen is tiring. Screen time can be very taxing, want to limit the time. That's a limitation of the online sources for online. Online is directed, answering questions you are already aware of.

\section{Interview 2}

\section{Interviewer: Daniella Kalinda}

\section{Interviewee: Curator at Mackenzie House}

D: What would you say is the ratio of researching online vs. handling the artifacts in person?

$\mathrm{N}$ : It is going up substantially as things are becoming more and more online and it's easier to find it and it's a much bigger time saver for me to be able to find what I'm looking for right here at my desk than for me to go and handle it. Archives, they have to 
limit the amount things that are handled and that can be very difficult. So as long as I can see it online and access it, it is a lot easier for me if I can do it from my desk.

D: What would you say are the benefits of working with physical ephemera or artifacts or archives vs. research online? I know that time-saver is one.

$\mathrm{N}$ : I mean, I think it's nice to see the original documents sometimes but it's actually much easier to do things online. When you're trying to figure out what something says, you can blow it up, and same thing with photos, you can blow it up so much larger on your computer than if you had the photo or the letter in front of you. It can be easier to do it on the computer. Then if we want to have it for an exhibit or for the public so that the public can handle it, they can still see the handwriting even though it's printed out, it's not the original document. With photos, you can make it big or small so actually for our use and communicating it with the public, it's great when it's online.

D: Do you find this is still true even with artefacts? Does that change with artifacts instead of ephemera?

$\mathrm{N}$ : It does. If I just want to know about something then it's ok to have a picture but if I want to communicate that with the public than really a 3D artifact is more meaningful than if it's just a photo of the artifact.

D: In terms of specific insights you're looking for in a special collection, what kind of information are you looking for, maybe with ephemera you're not looking for physical properties as you would with artefacts but we've heard a bit about the original owner...

$\mathrm{N}$ : We would want to know as much as we could about it. Whether it was historical documents. But, as you said, if it was a 3D artefact as well, we would want to know the size, where it was made, what it was made of, if there was a photo, great, and any kind of provenance about it is always helpful. I mean we can sometimes figure out things by 'maker's marks' and that sort of thing so we have to look those things up. 
$\mathrm{N}$ : So that's why when it's on the computer you can blow it up and control the light levels, it's not going to harm the document, as I said with ephemera, often online is a great way to explore those. Because you know when you're handling it, and then it can fall apart at your hands and then not only do you not get to figure out the information but no one else gets to see it again. So if it's scanned then you can look at, and as I said you can still see the writing. It's different to looking at what somebody else has typed out. I don't like to use somebody else's transcription because sometimes, they make a mistake.

D: Are there any different way that you would want to work with ephemera other than what currently exists?

$\mathrm{N}$ : Having more online would be great. Just because it is so easy to access them and manipulate them.

D: Do you have any experience working with augmented reality or virtual reality?

So we actually worked with the Interior Design department at Ryerson and we had some students who created alternate reality of the parlour and dining room area.

D: Did you guys use that as an exhibit here at the Mackenzie House?

$\mathrm{N}$ : We did. The problem that we had with it is that we only had it downloaded onto one phone and we had one viewer. So, it was amazing. It was incredibly detailed. It was fascinating but because we only had one viewer...only one person would look at it, and everyone else stands beside them looking and there was so much to see as they flipped through the time periods that you know, they could easily be looking at it for 10 minutes.

D: What would you think of, what we're looking at is creating an augmented reality app to help researchers while they're looking at artefacts or ephemera. Do you think this is something that's helpful for you for example when you're researching about different collections. 
$\mathrm{N}$ : I think that I'm not sure how, if a piece of paper would be so helpful but with 3D artifacts, it would be nice to look at all sides of it so that if there was a piece of ceramics you'd have a photo of it. You'd flip it upside down and you'd see the maker's marks of it. So you know you might now have a series of photos but I think it would be good if you could manipulate that artefact so that you can see all sides of it.

\section{Interview 3}

\section{Interviewer: Daniella Kalinda}

\section{Interviewee: Exhibition Curator at the Ryerson Image Arts Centre}

D: I was wondering, do you go visit them?

G: Yes, I was working on a project for a show and a book and the archive of the photographer was stored in Syracuse University, so I went to spend two weeks there, and spend like 8 hours a day in the archives to see everything they had. So it was from photographs to correspondence, ephemera, papers, the work that could be useful to understand the practice of the photographer. So yes I do visit.

D: How would you give us a ratio between how often you would work with the archives and ephemera itself vs. reading about it online?

G: I mean travelling is, time wise and budget wise, has more constraints. I do need to go online, I do need to do a pre-research to make sure that if I do travel it's worth it. So for me, having information online about the archive for example, is ideal. If the collection of the archive is catalogued, that's even better, and if it's accessible online, that's even better, but it doesn't prevent me from going and seeing the objects in person. So it's good for pre-research or post-travel it's good to have that, because you can work remotely, so that's ideal. But I do need to see the objects. 
D: If there were no limitations to how you're researching, how would you want it to be categorized? How would you want the ephemera to be made ready for you before you got into the research?

G: So online is ideal. Even if it is restricted access and I have to ask for permission, I do think catalogues online, databases, are really useful when you have to work remotely.

D: So what would you say are the benefits of working with the physical ephemera vs. the benefits of researching online?

G: The benefit for me is that I get to see the actual object. You get to touch it, feel it, look at the verso, look at the recto, you get a better sense of the size. But again it depends on what it is. If it's a photograph you get a sense of the preservation needs, conservation needs, can I show this object, is it in good condition to be shown, and with photography, you can really often because of the nature of the object and the prints. It is important to me to touch, even with gloves or protection, but I do like to have physical contact with it. But also because if my job requires that, maybe I'm going to show the object, so I kind of need to know what I'm going to show. So it is not always possible, sometimes we have travelling exhibitions and I don't see the objects prior to seeing them, but somebody else has because its a travelling exhibition, so I have to trust my colleagues that these are good objects to be shown.

D: Compared to researching online, what would you say are the benefits of that in comparison to holding it tangibly?

G: It saves time. It is two different moments in research for me. It is very distinct. I need the online access for obviously time reasons, budget reasons, also I can't be away from home for too long, these obvious reasons. I can go back to it, I can move the object - if I'm working on a database that already exists and I have the ability to move stuff around in my own filing system then it helps me in the research, I can make my own system that makes sense for the research. 
D: So I think my understanding is that you mainly look at open source databases for the ephemera. So is that pretty much how you research?

G: It's actually not that common for institutions to have complete accessible databases in my field. I don't know about other fields but in my field. Because photography comes with the idea of quantity, so it's very difficult to achieve a complete catalogue in digitization. I see it with art institutions where you have thousands and thousands of objects and it takes time. For example, we don't have a database that is accessible. People can't do research remotely, which is a problem. So we are working on that and trying to catalogue as much as we can, digitize as much as we can, and hopefully maybe have a database on our website that you can search through.

D: Now more on the technology side, when you're working with these photographs, what are you using during that time? So very practically, are you using a laptop?

G: Yeah, and my phone for the camera. I can sometimes have a tripod so the phone is on the tripod so I just have to press. So I can install the tripod and the phone and then I go through the papers and I just take the photos I need.

\section{Interview 4}

\section{Interviewer: Daniella Kalinda}

Interviewee: Digital Media Experience Coordinator at the Ryerson University Library

D: When you would go on site, what would be the ratio of how often you would be physically handling artifacts versus researching online?

$\mathrm{N}$ : Would never do research online, unless we were doing site backgrounds. We knew our stuff. If we recovered an artifact that we didn't recognize, then we would go to the physical literature. A lot of the good stuff isn't online. Most of it is physical. 
D: Before you got into digital archaeology, you were the one cataloguing the data. And now you are more using the catalogue that you find?

$\mathrm{N}$ : Sort of, yeah. The way it was working, we would have artifacts that had already been catalogued or at least analyzed. Then we would scan everything, then digitize it. Starting with artifacts that already existed. The goal was to have artifacts come in un-analyzed and then be able to analyze it through a system of some sort or 3D representation to analyze.

\section{Interview 5}

\section{Interviewer: Daniella Kalinda}

Interviewee: Curator at the Royal Ontario Museum, Professor at the University of Toronto

D: What would you say are the determining factors for you to go and travel and visit artifacts?

S: Research. Interest. Curiosity. These are the determining factors. It's like either I travel to see artifacts because they are connected to a research project that I am interested in or because they are things that I really love and maybe there is an exhibition that highlights something that I may not be actively working on but it is of great interest to me. Sometimes I would travel just because I'm curious to see, maybe a new display or a new installation, or you know it's like, it depends if the artifacts are exhibited in the public or if they are held in collections. So, the research part can be both exhibition and collections. The love or curiosity or love are mostly public displayed artifacts.

D: I'm interested how that works in your research process so if you're going to visit a specific archive, how do you end at that specific archive? Like are you researching online first and you're doing a broad literature review and then you end up going to visit? 
S: You know, I'm old enough to remember when you couldn't do an online research you just had to travel and go see an archive. But yes, it would be for sure the research now, it starts online but in reality there's lots of archives that aren't digitized and it's very very difficult to understand exactly what is there. Not every archive has a finding aid online. Sometimes the holdings are held somewhere but online you can't really determine what the extent of the holdings are. That's when you kind of have to move and hold and see. And there are things like colonial archives, historical archives that continue to be complicated to research so physical presence can greatly, can be very useful.

D: Which is my next question, what is the advantage of going and visiting the physical artifact versus learning about it online?

S: If ever an archive was fully digitized, then there would be no advantage. The problem is that archives in the majority of cases are not fully digitized. So, it's actually about being there in a room and being able to speak to an archivist and telling an archivist what you are interested in and actually being able to, let's say, benefit of the expertise of the archivist in order to find things that wouldn't otherwise be so easily findable.

D: And how do you collaborate with other researchers as a curator and as a researcher?

S: So I collaborate with curators on a number of collections because collections are not often available online. If I have something specific and I have questions about something that for example gets donated to the ROM, that I'm not able to identify or I don't know a lot about but I know that I have a colleague who's a specialist in the area then I would contact them and show them the image and get some immediate feedback on whatever I'm looking at and maybe some direction for the research and maybe some bibliographic references.

D: when you're preparing for an exhibition, how do you organize your data? I'm interested in the process of how you're working with artifacts. So when you're working with a couple different artifacts, in terms of the technology that you're using, are you 
having pictures on a Google Drive and keeping images of a certain number of artifacts that you refer to?

S: I use Dropbox a lot, so I would have Dropbox folders with images, I may do, actually I will do an Excel spreadsheet usually in which you have a smaller image of the artifact and the information, the basic information, you know what it is, where it is, and you know whatever other elements of interest that may sway/determine...another thing that's quite important is dimensions. Now we are using TMS. We are doing TMS reports and things like that.

D: Let's say if you're looking at specific library's archive and there's a QR code beside each picture so that you could see 3D visualizations on your table of that specific object, would that be helpful?

S: Maybe? I mean, yeah, if the quality of the imagery was quite faithful than yes it would. And I guess it would reduce the reason to travel to see objects if the rendition was faithful as it could be.

D: Are there any other technologies that you can think of that you've seen that could be interesting to add in your research or in the exhibitions but I'm thinking more for research?

S: No, but then again, you know it's like, it could be a generational thing, you know, it's like I'm a very old-digital learner so it really may be very different if you interview or ask this question to somebody who is a digital native, or close to a digital native. I got my first cell phone in my 30s. 


\section{Works Cited}

Adikari, S., McDonald, C., \& Campbell, J. (2013, July 21). Reframed Contexts: Design Thinking for Agile User Experience Design. Retrieved August 23, 2019, from https://link.springer.com/chapter/10.1007/978-3-642-39229-0

Babich, N. (2019, June 5). 7 Basic Rules for Button Design. Retrieved from https://uxplanet.org/7-basic-rules-for-button-design-63dcdf5676b4

Boehmer, J., Jung, Y., \& Wash, R. (2015). e Commerce Recommender Systems. The International Encyclopedia of Digital Communication and Society, 9999(9999), 1-8.

Ciecko, B. (2018, March 29). Museums are the best place to find innovation in AR. Retrieved from https://venturebeat.com/2018/03/27/museums-are-the-best-place-to-findinnovation-in-ar/

Ding, M. (2017). Augmented Reality in Museums. Arts Management and Technology Laboratory, 1-6. Retrieved from https://static1.squarespace.com/static/51d98be2e4b05a25fc200cbc/t/5908d019f5e2314ab 790c269/1493749785593/Augmented Reality in Museums.pdf

Feiner, S. K. (2002). Augmented Reality: A New Way of Seeing. Scientific American, 286(4), 48-55. doi: 10.1038/scientificamerican0402-48

He, Z., Wu, L., \& Li, X. (2018). When art meets tech: The role of augmented reality in enhancing museum experiences and purchase intentions. Tourism Management, 68(Complete), 127-139. doi:10.1016/j.tourman.2018.03.003

Katz, M. (2018, April 23). Augmented Reality Is Transforming Museums. Retrieved from https://www.wired.com/story/augmented-reality-art-museums/ 
Kohles, C. (2018, February 21). Augmented reality In Museums: 6 Success Stories.

Retrieved December 14, 2018, from https://www.wikitude.com/blog-augmented-realitymuseums/

Merriam-Webster (2019). Archive. Retrieved from https://www.merriamwebster.com/dictionary/artifact

Merriam-Webster (2019). Artifact. Retrieved from https://www.merriamwebster.com/dictionary/artifact Merriam-Webster (2019). Ephemera. Retrieved from https://www.merriamwebster.com/dictionary/artifact

Pardes, A. (2018, September 21). For Museums, Augmented Reality Is the Next Frontier. Retrieved December 14, 2018, from https://www.wired.com/story/museums-augmented reality-next-frontier/

Petrelli, D., Ciolfi, L., Dijk, D. V., Hornecker, E., Not, E., \& Schmidt, A. (2013). Integrating material and digital: A new way for cultural heritage. Interactions, 20(4), 58. doi:10.1145/2486227.2486239

Silva, T. S., Silveira, M. S., Melo, C. D., \& Parzianello, L. C. (2013). Understanding the UX Designer's Role within Agile Teams. Design, User Experience, and Usability. Design Philosophy, Methods, and Tools Lecture Notes in Computer Science,599-609. doi:10.1007/978-3-642-39229-0_64

UNESCO (2017). Tangible Cultural Heritage: United Nations Educational, Scientific and Cultural Organization. Retrieved from http://www.unesco.org/new/en/cairo/culture/tangible-cultural-heritage/

Vuforia Developer Library (2018). Vuforia Object Scanner. Retrieved from https://library.vuforia.com/articles/Training/Vuforia-Object-Scanner-Users-Guide 
Vuforia Developer Library. (2018). Multi-Targets. Retrieved from

https://library.vuforia.com/articles/Training/Multi-Target-Guide.html 